\title{
EL HABLA DE MADRID A FINALES DEL SIGLO XVIII SEGÚN LOS MADRILEÑOS ADOPTIVOS (1790)*
}

\author{
Elisabeth Fernández Martín \\ Universidad de Almería
}

\section{RESUMEN}

Este trabajo tiene por objeto el análisis de los fenómenos lingüísticos característicos del habla de Madrid presentes en el sainete manuscrito Los madrileños adoptivos (1790) de Antonio González de León, con el fin de determinar si pueden ser entendidos realmente como rasgos lingüísticos dialectales propios de dicha variedad en el siglo XviII. Para ello, en primer lugar, se ha realizado una contextualización de la obra, que permita llegar a comprender mejor su singularidad y ponderar su valor real como testimonio lingüístico; y, en segundo orden, se han analizado los fenómenos gráfico-fónicos, morfosintácticos y léxico-semánticos más llamativos, así como el sistema de trato representado en la obra, dado el interés que presentaba para la época y para el conocimiento de esta variedad lingüística.

Palabras Clave: siglo XVIII, sainete, habla de Madrid, madrileñismo, a por.

\section{THE LINGUISTIC VARIETY SPOKEN IN MADRID IN THE LATE 18TH CENTURY ACCORDING TO LOS MADRILEÑOS ADOPTIVOS (1790)}

\section{Abstract}

The focus of this study is to analyse the characteristic phenomena of the linguistic variety spoken in Madrid presented in the manuscript of the short comedy Los madrileños adoptivos (1790), by Antonio González de León, in order to determine if these elements can really be known as dialect linguistic features of that variety in the $18^{\text {th }}$ century. For this, firstly, a contextualization of the work has been carried out, which allows us to understand its uniqueness and ponder its real value as a linguistic testimony. Secondly, the graphic-phonic, morphosyntactic and lexical-semantic phenomena represented in the comedy have been analysed. Furthermore, the address system has been explained, due to the interest that it has at that time and to the knowledge of this linguistic variety.

KEYWORDS: $18^{\text {th }}$ century, short comedy, Spanish spoken in Madrid, vocabulary of Madrid, a por. 


\section{INTRODUCCIÓN. LOS MADRILEÑOS ADOPTIVOS COMO TESTIMONIO LINGÜÍSTICO}

El sainete Los madrileños adoptivos fue compuesto en 1790 por Antonio González de León (1742-1818), un polifacético erudito sevillano․ Esta pieza nunca llegó a publicarse, por lo que su difusión fuera de las fronteras de la capital hispalense tuvo que ser realmente muy limitada. Aunque su autor no era un escritor relevante dentro del panorama nacional de finales del siglo XVIII, su producción, tanto de poemas como de obras teatrales, sí fue conocida en la Sevilla de la época, "como manifiestan los muchos [textos] que de este género poseen los aficionados" (Matute y Gaviria 2007 [1888]: 68). El reducido alcance de Los madrileños adoptivos hizo que solo se conservara un único ejemplar manuscrito del texto-localizado en el fondo antiguo de la Biblioteca Nacional de España ${ }^{2}-$. Recientemente, se ha realizado una edición de la obra (Fernández Martín 2016a), que es la que se utiliza y cita en el presente trabajo.

La actividad como dramaturgo del autor se inicia en el contexto de la reforma ilustrada del teatro que impulsó Pablo de Olavide durante su estancia en Sevilla; de hecho, Antonio González de León era uno de los miembros destacados de la tertulia que el político reunía en los salones del Alcázar. Por tanto, hay que situar la presente obra dentro de un nuevo gusto poético, renovador, fruto del sincretismo entre las distintas visiones que habían dominado todo el panorama literario del siglo xviII. A finales de dicha centuria, se pretendió crear una especie de «sainete ilustrado» (o «sainete nuevo», como lo denomina el propio González de León) con el que reorientar la función pedagógica de este tipo de obras que habían sido duramente criticadas a lo largo de todo el setecientos. No se trata, por tanto, de un sainete similar a los de Ramón de la Cruz, dirigido a un gran público popular, sino de una obra que se representó ante un reducido grupo de la élite sevillana y donde la comicidad emana de un humor refinado, fruto de un juego e intercambio lingüístico entre los perso-

* Una versión preliminar y abreviada de este trabajo fue presentada como conferencia de clausura en las Jornadas La lengua de Madrid ayer y hoy, organizadas por el Proyecto S2015/HUM3443-ALDICAM CM, celebradas en la Universidad de Alcalá de Henares (Madrid), durante los días 28 de febrero y 1 de marzo de 2019.

${ }^{1}$ Antonio González de León pertenecía a una conocida familia de eruditos sevillanos, los González de León: su tío era canónigo y se dedicó a la escritura como biógrafo, bibliógrafo e historiador, mientras que su padre, Francisco González de León (1706-1761), fue un importante médico y un escritor precoz. Antonio, por su parte, ostentó ciertos puestos administrativos y de responsabilidad en la ciudad: contador en las Reales Fábricas de Tabaco, oficial del Archivo General de Indias y, en 1809 -en plena guerra contra los franceses-, la Junta Central lo nombró comisario de guerra honorario, así como también fue miembro honorario de la Academia de Buenas Letras de Sevilla y de la Academia Horaciana. Antonio era, pues, un hombre de cierta posición social, que poseía una fina sensibilidad lingüística e inquietudes literarias. Acerca de su vida y obra, véanse los trabajos de Aguilar Piñal (1974: 79, 81, 122-123, 141; 1986: 309-312), Matute y Gaviria (2007 [1888]: 66-68) y Fernández Martín (2016a: 24-45).

${ }^{2}$ Véase la ficha catalográfica de la BNE (MSS/14602/3), accesible en $<$ http://catalogo.bne. es/uhtbin/cgisirsi/?ps=um4VrAD3nn/BNMADRID/41350687/9>. 
najes. Asimismo, la extensión del texto (1461 versos) también es mucho mayor que la de otros sainetes de la época, de ahí que casi sea posible considerarlo «una comedia en un acto» (Herrera Navarro 2008: 804).

En cuanto al tema, Los madrileños adoptivos trata de la emigración a Madrid de las gentes de provincias, así como de su proceso de integración social y acomodación lingüística en la compleja vida de la capital. La obra se organiza a través de un diálogo entre dos grandes grupos de personajes: los sevillanos (don Patricio, doña María y don Hilario) y los madrileños (don Simón, doña Paquita, doña Petra, don Pepito y don Juanito), aunque estos últimos son realmente madrileńos de adopción; es decir, forasteros que habían emigrado a la Corte tiempo atrás en busca de nuevas oportunidades laborales y en un claro afán por lograr el ascenso social. En el propio sainete se da cuenta de la procedencia dialectal de algunos de ellos; así, se indica que don Simón es castellano, concretamente, de Aranda (de Duero); don Juanito es de Daimiel, en La Mancha; y don Pepito de «hacia Burgos» (vv. 812-814). Una vez instalados en la gran capital, estos madrileńos de nuevo cuño alababan las bondades de Madrid, se convertían en imitadores de las clases mejor situadas a las que querían asemejarse y eran seguidores de las nuevas modas, especialmente las venidas desde Francia.

No obstante, dicho proceso de acomodación, tanto del lenguaje como de las costumbres, no siempre era de convergencia plena. Estos inmigrantes teñían su discurso de ciertos elementos castizos y vulgares en los que se puede entrever, en determinados casos, su origen dialectal ${ }^{3}$ y se revela, de manera más evidente, la humilde cuna de la que provenían. Como ya advirtió Navarro Tomás (2004: 9) a principios del siglo xx, en Madrid se ha dado la circunstancia de que la clase intelectual -aunque no solo esta-, siendo en su mayor parte de origen provinciano, ha adoptado espontáneamente la pronunciación cortesana, «ocultando cada uno, como mejor puede, las huellas fonéticas de su tierra natal». Esta circunstancia parecía darse también ya a finales del xviı, como consecuencia del elevado número de inmigrantes que recibió Madrid en ese período, procedentes en su mayor parte de las dos Castillas, el norte peninsular (Asturias, Galicia, León y País Vasco) y la pro-

${ }^{3}$ Ciertamente, es difícil saber si alguno de los fenómenos que se atribuyen a estos nuevos madrileńos puede estar motivado por el origen dialectal del personaje. En principio, hay que tener en cuenta que se ofrecen como rasgos lingüísticos propios de la capital a finales del setecientos, lo que cabe pensar que, si González de León los utilizó para caracterizar a los personajes, serían de uso generalizado entre, al menos, determinados sectores de la población madrileńa. Por otra parte, de algunos personajes (dońa Paquita y dońa Petra) no se indica una procedencia geográfica concreta, por lo que cabe pensar que este aspecto no tendría que ser especialmente relevante para los usos madrileños seńalados. No obstante, en algún caso, como el uso de guapo aplicado a cosas, que en los ejemplos corresponde solo a un personaje (don Simón) -que alude, por ejemplo, a las «fiestas guapas» que se hacen «en mi lugar» (vv. 419-420)-, cabe considerar este hecho y plantearse hasta qué punto este rasgo lingüístico podría corresponder a Madrid o estar motivado también por el origen dialectal del personaje. 
pia provincia de Madrid ${ }^{4}$. Dicha población le confirió a la capital -y, por ende, a su manera de hablar- una naturaleza especial.

La oposición entre Sevilla y Madrid debe ser interpretada como la representación paradigmática y opuesta de las dos visiones de pensar, vivir y expresarse en la España del setecientos. Por un lado, Sevilla, que no era la Sevilla de antaño y había perdido la bonanza económica de otras épocas, es la que representa en la obra la identidad tradicional en declive; por otra parte, Madrid constituía un foco de atracción para el resto de regiones españolas y se erigía como centro de prestigio a la vanguardia de las modas sociales y culturales de finales del setecientos.

Así pues, el diálogo gira en torno a las diferencias que existían entre los usos y las costumbres empleadas por los miembros de estas dos comunidades de habla, esto es, entre la manera de hablar y comportarse en Madrid frente a la de Sevilla -y, por extensión, Andalucía-. Como podemos imaginar, la elección de esta oposición -expuesta en el conocido trabajo de Menéndez Pidal de 1962- no es ni mucho menos arbitraria, teniendo en cuenta lo que representan histórica y lingüísticamente ambas ciudades para numerosos fenómenos de trascendencia fundamental en la historia del español.

De este diálogo entre ambos grupos de personajes se puede extraer una serie de rasgos caracterizadores de ambas variedades lingüísticas, ya que cada uno manifiesta de manera evidente lo que le parece vulgar, incorrecto y anticuado o censurable, frente a lo que le es familiar, correcto y actual. En el presente trabajo, nos centramos únicamente en aquellos fenómenos que se apuntan como propios del habla de Madrid 5 , con el objetivo de desentrañar si pueden considerarse caracterizadores dialectales ${ }^{6}$ de esta variedad lingüística -aunque no sean exclusivos de ella-,

${ }^{4}$ Madrid vivió una fase de crecimiento elevado poco antes de mediados del siglo xviII, lo que coincidió con un incremento de la afluencia inmigratoria. Esta inmigración estaba formada principalmente por hombres de mediana edad solteros. No obstante, a partir de la segunda mitad del setecientos, el número de mujeres inmigrantes fue en aumento, principalmente con motivo de su entrada en el servicio doméstico, espacio que había estado reservado a los hombres hasta ese momento. Esta demanda creciente de servicio femenino trajo como consecuencia el comienzo de la estabilización de la población. Al haber más mujeres, se realizaban más uniones matrimoniales y, en consecuencia, se produjo un descenso de la inmigración temporal para el siglo xix (Carbajo Isla 1985).

${ }^{5}$ Los rasgos lingüísticos achacables a los personajes andaluces fueron abordados en Fernández Martín (2016b: 57-59).

${ }^{6}$ Seguimos el concepto de caracterizador dialectal planteado por Company Company (2007: 6), quien define este tipo de fenómenos como «rasgos propios de un individuo o colectividad que los caracteriza frente a los demás». En este sentido, se entiende por caracterizador dialectal madrileño aquel rasgo que singulariza al hablante de Madrid frente a otros hablantes (en la obra, los sevillanos). Debe entenderse, no obstante, que las características que se van a señalar no son propias solamente del habla urbana de Madrid, sino que, en buena medida, se dan también en las hablas castellanas del centro peninsular o, incluso, son ejemplos de variación diastrática generalizados a todas las variedades del castellano en hablantes de bajo nivel cultural, como ocurre con las metátesis o las alteraciones del timbre vocálico. 
especialmente en el momento en el que dicha variedad se podía entender como tal ${ }^{7}$. Algunos de estos elementos son descritos y censurados por los personajes sevillanos -es más, aparecen subrayados en el original del manuscrito-, otros son expuestos por los propios madrileńos y, finalmente, unos pocos pasan más desapercibidos y se muestran, sin advertencia alguna, en las intervenciones de estos últimos personajes.

Por último, antes de pasar a analizar estos rasgos lingüísticos, conviene dejar constancia también de que se está estudiando la lengua de unos personajes determinados, en un tipo de literatura específica (un sainete), con un interesante componente cómico y en un período concreto, hechos que, en cierta medida, pueden determinar la amplitud de las afirmaciones lingüísticas que se realicen, aunque se trate, como ya se ha explicado, de una pieza singular, escrita por un autor aficionado a las letras y no por un gran genio literario. No obstante, no se puede olvidar tampoco que la lengua, como elemento caracterizador de los personajes en el teatro, ha constituido un recurso literario más que, desde Lope de Rueda, ha estado presente en las letras espańolas y gracias al cual se han realizado muchas y muy valiosas aportaciones para el estudio de la historia de la lengua española. No es el objetivo de este trabajo el reivindicar el estudio de la lengua a partir de fuentes literarias -algo que excede en mucho el objetivo de cualquier publicación de este tipo-, sino analizar los rasgos lingüísticos que pueden ser tenidos en cuenta como caracterizadores del habla madrileña de finales del setecientos, $y$, como podrá deducirse del análisis a continuación, este texto es, sin duda, una fuente esencial para estudiar el habla madrileña dieciochesca.

\section{RASGOS LINGÜÍSTICOS CARACTERIZADORES DEL HABLA DE MADRID EN LA OBRA}

El enfrentamiento entre los distintos grupos de personajes ofrece como resultado una interesante descripción que afecta a diferentes niveles lingüísticos: fónico, morfosintáctico, léxico-semántico e, incluso, fraseológico y pragmático. Lo más llamativo es que algunos de estos elementos que diferenciaban a los personajes madrileńos de los sevillanos a finales del xvıı siguen siendo considerados identitarios del habla de Madrid en la actualidad. Asimismo, también es interesante comprobar cómo otros fenómenos son hoy generales en español, por lo que, o bien estaban más extendidos a nivel dialectal en ese momento, o bien fue la capital, como centro de irradiación lingüística de prestigio, la que contribuyó a su generalización posterior.

En cuanto a los caracterizadores dialectales fonético-fonológicos, uno de los que más se destaca en la obra lo constituye las distintas realizaciones del fonema dental - $d$ en posición final, que vacila entre la dental sorda, como se ve en Madrit

7 La denominada habla de Madrid constituye una entidad compleja de la cual no es fácil determinar su cronología o no hay, al menos, un consenso generalizado sobre sus primeras manifestaciones como variedad diferenciada. Así, por ejemplo, García González (2018) considera que sus primeras documentaciones se pueden encontrar a finales del siglo Xvir y la primera mitad del XIX, mientras que González Ollé (2003) plantea que ya se pueden ver rasgos del habla de Madrid a finales del Xvir. 
(1a, 1c) o vanidat (1b), y el refuerzo fricativo de Madriz (1c), fenómeno este no solo exclusivo del habla de Madrid, sino presente en el castellano del centro y del norte peninsular (Hernández Alonso 1996: 200; Pensado 2000: 51) ${ }^{8}$. El debilitamiento de esta consonante final también se puede traducir en una pérdida, como se muestra en los ejemplos de verdá y usté (1d) y como ocurre con frecuencia hoy día en el habla de Madrid (Moreno Fernández 1996: 216; Molina Martos 2010a: 98-100).

(1)
a. D. Patricio.
D. Simón.
¿De dónde?
¿Quién?, ¿yo?
De Madrit, corte de España (vv. 34-35).
b. D. Simón.
Eso es echar vanidat,
c. D. Patricio.
como andaluz, a tenajas (vv. 245-246).
Y sobre todo, el sentido
nos rompen y nos taladran
con su Madrit en t [e] fuerte
d. D. ${ }^{\text {a Paquita. }}$
D. Pepito.
o Madriz en z[eta] larga (vv. 1127-1130).
¿No es verdá usté, don Pepito?
¿No es verdá usté?
Verdad clara (vv. 675-676).

Es curioso este último ejemplo (1d), en el que destaca la diferente realización de la $-d$ final por parte de cada uno de los dos personajes madrileños adoptivos. La mujer la suprime de su pronunciación, mientras que el hombre no la omite. Esta caracterización quizá podría ser un patrón sociolingüístico diferenciado en la época, si se considera -con las reservas oportunas- que esta diferencia en lo escrito representa un reflejo directo de lo hablado y que se trate de un hecho intencionado por parte del autor ${ }^{9}$. No obstante, también hay ejemplos de eliminaciones en otro de los personajes masculinos, el «castellano ramplón y testarudo» don Simón (2) -quien alterna esta omisión con la pronunciación de $-t$ final (cfr. 1b)-:

8 También se refleja esta pronunciación interdental en las muestras de escritura inhábil de los textos de beneficencia madrileños dieciochescos (Sánchez-Prieto Borja y Vázquez Balonga 2019: 103), de lo que se puede deducir que este era ya un fenómeno presente en la región desde al menos el setecientos. Para el siglo xx, esta pronunciación parece estar mucho más extendida, a juzgar por las afirmaciones de Quilis (1966: 369): «Toda [-d] implosiva se convierte en [- $\theta$ ]: Madriz, verdaz, etc. [...] Este fenómeno está muy extendido en Castilla la Vieja, pero no en la misma medida en la Nueva, con excepción de Madrid o algunas otras ciudades donde la influencia de la capital es notoria». Por su parte, Flórez (1966: 157) matiza que «La $d$ final se oye a menudo pronunciar como $z$ castellana, inclusive entre personas muy cultas: la paréz, los abazes 'abades', Madriz-Alcalá, la Ciudaz-encantada, etc.».

${ }_{9}$ No parece tan improbable si se tiene en cuenta que, como afirma Paredes García (2006: 227), existen actualmente zonas de Madrid donde las mujeres propician la pérdida: «En el noroeste de Madrid, donde la tendencia general es a conservar las consonantes en posición implosiva, la pérdida de la -/d/ final la propician los hablantes más instruidos y las mujeres». 
(2)
D. Simón. $\quad Y$ en la metá de Castilla.
D. Hilario. ¡Metá!... pues no ha visto nada (vv. 1059-1060).

Simón no es hombre instruido, como se puede deducir de la vacilación de átonas que acusa en su intervención. Se trata de un «hijo prohijado de Madrid», uno de tantos ciudadanos de Castilla que emigra a la capital con el objetivo de prosperar vitalmente. Su bajo estatus social queda expuesto cuando habla, un hecho que claramente no pasa desapercibido para el «bromoso y camastrón» don Hilario.

En general, los personajes «venidos de Madrid» representados en la obra proceden del pueblo llano -aunque intenten mostrarse como miembros de la burguesía acomodada-, por lo que el nivel de lengua que exhiben dista mucho de ser culto o refinado. Así se puede comprobar en el siguiente parlamento, repleto de vulgarismos, de don Juanito (3):
D. Juanito. Yo tampoco estaré mucho, que sigún vacante haya drento o en la dirección, me voy, me la dan sin falta, que el diretor y el menistro son vesita de mi ama.
D. Hilario. ¡Diretor, vesita y drento, menistro y sigún! ¡Aguanta! (vv. 743-750).

De entre estos "gazapos» -tal y como se denominan en el propio sainete-, merece la pena destacar, por su número, la continua reiteración de vacilaciones en el timbre de las vocales átonas que se da a lo largo de todo el sainete ${ }^{10}$ : cerimonias, dispensas, fantesía, nenguno, menistro, misiricordia, ofecina, peojerias, tenajas, rediculez, sisión, etc. (en lugar de ceremonias, despensas, fantasía, ninguno, ministro, misericordia, oficina, piojerías, tinajas, ridiculez, sesión). Son llamativas también las aféresis y síncopas de distintos elementos (eja y drecho por deja y derecho), como se ve en (4a); las metátesis (estógamo, Flugencio por estómago, Fulgencio), sobre todo de vibrantes (catredal, drento, frábica, trempano en lugar de catedral, dentro, fábrica,

${ }^{10}$ La vacilación de átonas es un fenómeno ampliamente documentado en la historia de la lengua española, aunque fue muy abundante en el español preclásico, período en el que «existía cierta vacilación, en sílabas átonas iniciales e interiores, entre vocales cerradas $(/ \mathrm{i} /, / \mathrm{u} /)$ y medias $(/ \mathrm{e} /, / \mathrm{o} /) \mathrm{de}$ ambas series» (Penny 2004: 597). Tales vacilaciones fueron disminuyendo durante los Siglos de Oro, como consecuencia de la presión que ejerció la lengua escrita, especialmente a través de las obras literarias, así como la creación posterior de la Academia, lo que permitió fijar los casos de vacilación y establecer qué variantes eran las prestigiosas y cuáles quedaban relegadas hasta hoy a diversas zonas rurales del ámbito hispánico (Cano Aguilar 2004: 826). En el caso del Madrid dieciochesco popular parece tratarse de un fenómeno aún muy extendido que afectaba sobre todo a las vocales anteriores y a la baja y media (a/e), como han documentado Sánchez-Prieto Borja y Vázquez Balonga (2019: 101). 
temprano); ${ }^{11}$ y la simplificación de grupos cultos (diretor por director) $)^{12}$, según se muestra en (4b y 4c; cfr. 3).

(4)

a. D. Hilario. ¿Pedrique?, ¿so pone faltas?

Pues ustedes que se engullen

la mitad de las palabras:

eja, icir, drecho, exprimento,

son bachilleres de panza (vv. 1084-1088).

b. D. Patricio. ¿Vieron ustedes la iglesia?

D. ${ }^{a}$ PaQuita. ¿La catredal?, no me agrada.

D. Hilario. Apunte usté, catredal (vv. 375-377).

c. D. Petra. ¿Tan trempano? (v. 1439).

Algunos de estos ejemplos vulgares han sido utilizados por diferentes autores posteriores para caracterizar el habla madrileña: bien del Madrid popular de antaño, como ocurre con catredal (4b) -uso del cual se quejaba Clarín en 1896 (vid. infra)-, bien del Madrid rural de hoy, como sucede con la voz tenaja, forma estigmatizada que García Mouton y Molina Martos (2017: 210) recogen en el sur de la Comunidad de Madrid, frente a la solución más instruida, tinaja, que la sustituye en la mayor parte del habla rural madrileña ( $c f r$. ADiM: mapa 723). No obstante, ambas palabras (catredal y tenaja) son formas vulgares corrientes en español ${ }^{13}$, al igual que el resto de fenómenos (alteraciones en el timbre vocálico, aféresis, síncopas, metátesis y simplificaciones de grupos cultos) son rasgos generalizados en todas las variedades del castellano en hablantes de bajo nivel cultural.

Otro fenómeno consonántico estudiado con frecuencia desde la perspectiva de su expansión en el habla de Madrid es el yeísmo (Quilis 1966: 370; Moreno Fernández 1996: 219-220; Molina Martos 2006: 132 y ss.), del cual se registra un ejemplo en la obra en boca de una de las mujeres venidas de la capital (5). Aparece resaltado en el texto, pero, a diferencia de lo que ocurría con los fenómenos anteriores, no se trata de un rasgo lingüístico censurado por los personajes sevillanos. La inclusión de este ejemplo podría deberse a que doña Paquita intenta imitar el habla de los sevillanos para burlarse de ellos -aunque la pronunciación andaluza yeísta no se refleja en las intervenciones de los personajes sevillanos-, como ocurre con otros fenómenos, por ejemplo, la aspiración de la $h$ - procedente de la $F$ - latina (cfr. Fernández Martín 2016b: 57), pero también podría entenderse como reflejo de su propia pronunciación. Es posible pensar que el yeísmo ya había penetrado en

11 También constatados en el xviıI por Sánchez-Prieto Borja y Vázquez Balonga (2019: 106).

12 Cfr. Sánchez-Prieto Borja y Vázquez Balonga (2019: 107-108).

13 Baste, por ejemplo, hacer la consulta de la voz catredal en el Fichero general de la Real Academia Española (47 cédulas) o en los corpus digitales (por ejemplo, el CORDIAM) para comprobar lo habitual que resultaba esta forma entre el vulgo de cualquier zona del dominio hispánico, así como consultar tenaja en otros atlas lingüísticos, como pueda ser el ALeCMAn (II, mapa 611), para constatar que es posible localizar esta forma en una geografía lingüística mucho más amplia. 
el habla popular madrileña en el siglo xviıI, lo que parece plausible teniendo en cuenta los datos documentados para principios del ochocientos por Sánchez-Prieto Borja y Vázquez Balonga (2019: 114) ${ }^{14}$.

(5)

D. ${ }^{a}$ Paquita. ¡El diantre del seviyano!, cómo corta, cómo raja (vv. 883-884).

Respecto de otros fenómenos de naturaleza fonética que se han abordado en el estudio del habla de Madrid, tanto en los trabajos actuales de corte sociolingüístico (Molina Martos 2015; Paredes García y Molina Martos 2019: 61-65, entre otros) como en la documentación histórica (Sánchez-Prieto Borja y Vázquez Balonga 2019: 105), cabe mencionar el caso de la aspiración de la -s implosiva -o su asimilación y elisión-. No se encuentran ejemplos en la obra entre los personajes madrileños -aunque sí es un rasgo que estos critican a los andaluces-, por lo que bien podría tratarse de un fenómeno meridional conocido en Madrid, pero de moderna adopción y avance más lento, desprestigiado en el siglo Xviı entre los hablantes de la capital ${ }^{15}$.

En cuanto a los caracterizadores dialectales de tipo morfosintáctico, un fenómeno que se documenta en la obra (6) y que se señalada también comúnmente en los trabajos sobre el dominio geográfico madrileño (Quilis 1966: 372; García Mouton 2007 [1994]: 30; Paredes García 2006: 228) es el empleo de la locución a por, frente al uso aislado de la preposición ( $p o r)$, tras verbos que indican movimiento $(v . g r$. ir, salir, venir, volver): vienes a por agua, vas a por pan... La utilización de esta secuencia preposicional con el sentido de 'en busca de' ha sido desaconsejada hasta época reciente en la norma culta espańola, aunque hoy se admite su empleo (DPD: s. v. $a^{2}$ :

${ }^{14}$ Los estudios dialectales y sociolingüísticos sobre el habla de Madrid han explicado como meridional (andaluz) el origen del yeísmo madrileño ( $c f r$. Moreno Fernández 2004: 987), así como se han ocupado de aclarar las condiciones sociolingüísticas que pudieron favorecer la difusión de este cambio en el habla de Madrid (Molina Martos 2006: 133), entre las cuales cabe destacar la influencia de la emigración andaluza en el habla popular de la capital -a la que también se puede sumar la tendencia de la clase alta madrileńa a mezclarse con el pueblo llano e imitar su manera de hablar y el prestigio que ha ejercido la modalidad urbana (desde la que se han irradiado las innovaciones) sobre el medio rural-. No obstante, a juzgar por la información histórica existente, cabe pensar en una cronología -o influencia- más antigua para el yeísmo madrileño o, al menos, para el que demuestran las clases más populares.

15 En otros textos literarios de autores madrileños coetáneos la situación es similar, como recoge García González (2018: 1575). Así, los escasos ejemplos presentes en los sainetes de Ramón de la Cruz y en las obras del XIX estudiadas en su corpus son identificados como andaluces. Estos resultados contrastan, sin embargo, con la documentación archivística de beneficencia madrileña, donde, según Sánchez-Prieto Borja y Vázquez Balonga (2019: 105), «la aspiración de la [-s] final estaba muy extendida». Para el siglo xx, los trabajos de naturaleza sociolingüística ( $c f r$. Molina Martos 2015; Paredes García y Molina Martos 2019: 61-65, entre otros) han revelado un porcentaje de casos de aspiración considerable en distintas zonas de la Comunidad (Getafe, Alcalá de Henares y Vallecas), motivados por el origen social y dialectal del hablante. La aspiración también está presente en la propia ciudad de Madrid, aunque esta sigue siendo conservadora en el contexto de la región, puesto que el mantenimiento de la /-s/ alcanza un $82 \%$ en el barrio de Salamanca, en el centro de la capital. 
2. a por). No obstante, su uso alterna con por (ve por agua, salgo por el pan, volvió por el paraguas) en el español de Espańa, pero no en el de América, donde a por se percibe como anómalo y sigue siendo general el empleo exclusivo de la segunda preposición. Este españolismo peninsular actual parecía ser un madrileñismo en el XVIII si tenemos en cuenta las críticas que realizan los personajes sevillanos en la obra:
D. Hilario.
[...] y nos rallen las entrañas
con su por ahi $i^{16}$, anda ves,
va a por vino, va a por agua,
y que si a un pobre andaluz
se le escapa por desgracia
aspirar fuerte la h[ache],
le fulminan una causa,
como si el pobre dijera
una blasfemia nefanda (vv. 494-501).

Company Company y Flores Dávila (2017) consideran que la combinación preposicional de a por consistió en una innovación madrileña del primer tercio del siglo XIX, la cual sufrió un incremento paulatino y sostenido a lo largo de dicha centuria hasta alcanzar su generalización a mediados del siglo xx. Sin embargo, si se toma en consideración lo que apunta el texto de Los madrileños adoptivos, habría que retrasar su origen hasta el siglo XviII, período en el que, como vemos, se trataría de un fenómeno propio de las capas populares de la capital, desde las que se extendería al resto de la población y, de ahí, posteriormente, a la periferia peninsular. Así, a finales del ochocientos, había autores (incluso académicos de la lengua) que utilizaban a por en sus versos, hecho que escandalizaba a quienes, como Clarín, consideraba vulgar esta combinación de preposiciones:

Dice Manuel del Palacio, de la Academia Española: hablaban de palos; ¿irán á por ellos? ¡Ir á por! Eso ya no lo dicen ni las pobres chicas, las que tienen que servir. ¡Un académico diciendo ir á por! Y no es errata, porque la preposición á ocupa su sílaba indispensable para el verso. Y todavía dirá Palacio que hablo en estilo de taberna griega, porque me escandalizo ante ese ir á por. Todo les parece pedantesco á estos poetas populares, espontáneos y sin cultivo, menos haiga, el omega, catredal y el ir á por (Leopoldo Alas Clarín, «Palique», Madrid Cómico, 1896, Madrid; apud Company Company y Flores Dávila 2017).

En relación con este ejemplo (6), se puede comentar también el caso de la locución adverbial por ahi o, mejor dicho, por abi, con pronunciación diptongada (/ái/). Es muy probable que esta construcción lexicalizada adquiriese ciertas con-

${ }^{16}$ Enmendamos la acentuación, que aparece en la edición del texto (por ahí), ya que en el manuscrito original se escribe como diptongo (porài) y esta es también la pronunciación adecuada según la métrica octosilábica de los versos. 
notaciones negativas a finales del XVIII, no en vano con la combinación de por ahi se denotaba una cosa común y poco recomendable (DRAE 1803: s.v.ahi; NTLLE) y se llamaba así «á las cosas muy vulgares» (Castro y Rossi 1852: s. v. ahi; NTLLE). Además, según afirmaba Castro y Rossi, el adverbio ahi «Precedido de las preposiciones de y por sirve para denotar que en una persona nada hay de notable». Por su parte, Domínguez (1853: s. v. ahi; NTLLE) explica que por ahi quería decir «entre el vulgo, entre el pueblo. v.g.por ahi se dice, por ahi se zuzurra, etc.» y recoge también su uso para indicar indeterminación de lugar: «Por cualquier parte, por donde quiera, á la ventura, etc.: v.g. me voy por ahi ó ahi». En el $D R A E$ de 1884 (s. v. ahi; $N T L L E)$ se añade la expresión por ahi, por ahi con el significado de 'poco más o menos' y, ya a finales del XIX, en el Diccionario enciclopédico de la lengua castellana (1895), de Zerolo, Toro y Gómez e Isaza, encontramos una definición en la línea del ejemplo analizado (s.v.ahi; NTLLE):

Por ahí. Además de la indeterminación de lugar (V. 1), indica este modismo proximidad del sitio en que nos hallamos.

[...] OвSERv. Generalmente se pronuncia en dos sílabas; pero cuando va en verso íntimamente ligado con la palabra que le sigue, puede pronunciarse como monosílabo.

Pues sobrinita ahi te dejo. (Mor. [= Leandro Fdez. de Moratín, La mojigata]) ¡Ahí es un grano de anís (ibidem).

Esta misma dislocación acentual del teatro en verso que se comenta en el Diccionario enciclopédico es la que se utiliza en la obra Los madrileños adoptivos, pero ¿se trataría acaso de un uso exclusivo del teatro versificado dieciochesco? No parece que sea así, sino que más bien pueda tratarse de un uso coloquial corriente ya en la lengua oral madrileña de la época. La pronunciación diptongada es común hoy día en el habla popular o vulgar de buena parte de España e Hispanoamérica (NGLE: 17.8j; Carricaburo 2010: 369) y se da también en diversas construcciones lexicalizadas o semilexicalizadas en las que está integrado el adverbio de lugar $a h i$, como en el caso de por ahi (empleada para señalar un lugar o zona imprecisa, un cálculo o estimación aproximada, incluido un tiempo indefinido -en buena parte de América presenta un significado epistémico similar a 'tal vez', 'a lo mejor'- ${ }^{17}$ ), ahi está (usada para enfatizar en el diálogo alguna declaración previa), vete por ahí (como fórmula imprecativa) y ahi, ahi (con el significado de 'aproximadamente igual'); así como en aquellos casos en los que ahi está desemantizado y desempeña un valor expletivo (v. gr. ahi nos vemos, ahi me llamas cuando llegues...).

Otro fenómeno morfosintáctico interesante que también se muestra en el ejemplo de (6) es la presencia de una $-s$ analógica en el imperativo de segunda persona del verbo ir (ves), rasgo señalado en alguna ocasión como característico del habla castellana popular (García Mouton 2007 [1994]: 30) y que, como vemos, también se daba en el Madrid del siglo XviII.

17 Acerca de la evolución semántica de ahi y por ahí como consecuencia de la dislocación acentual, puede verse el trabajo de Di Tullio (2013), a partir de ejemplos del español de la Argentina. 
Más relevante, por tratarse de un elemento de gran representatividad en el patrón lingüístico madrileño, es el laísmo. Aunque su aparición no es frecuente en el texto, se registra algún caso de laísmo de persona en el discurso femenino (7). Su uso estaba muy extendido durante los siglos XVII y XVIII, incluso entre escritores notables, de ahí que llegara a gozar de cierto prestigio social en la segunda mitad del setecientos (NGLE: 16.10b). Este hecho explica que González de León lo utilizara en su obra para caracterizar el habla de Madrid, pero que los personajes sevillanos no lo consideraran reprobable.

$$
\begin{array}{ll}
\text { D. }{ }^{a} \text { Petra. } & \text { A la reina la habla } \\
\text { esta como a mí (vv. 328-329). }
\end{array}
$$

Otro fenómeno menos conocido y estudiado, pero que, sin duda, podría tratarse de un posible cambio en marcha en la época, es el uso del adjetivo guapo aplicado a entes inanimados (guapa tierra, fiestas guapas, iglesia guapa...) con el significado de 'bonito, precioso, agradable' (8). Se atestigua, con cierta reiteración en el texto por parte de don Simón, como una novedad popular que llama la atención de los andaluces.

(8)
a. D. Simón.
Mi tierra sí es guapa tierra, no esta de aquí, mala y cara (vv. 123-124).
b. D. Simón. ¡La de mi lugar sí es guapa! (v. 528).
c. D. Simón.
En mi lugar por las Cruces
se hacen unas fiestas guapas, y los mozos y las mozas, voto a san, y cómo bailan (vv. 419-422).

Hoy en día este uso es muy frecuente en el lenguaje popular y juvenil ${ }^{18}-$ de hecho, aún no se recoge en el diccionario académico-, aunque cabe preguntarse desde cuándo funciona así. Si consultamos los primeros ejemplos que ofrece el Corpus Diacrónico del Español (CORDE), estos corresponden también al siglo XVIII y se localizan en los sainetes de Ramón de la Cruz y en la Historia del famoso predicador Fray Gerundio de Campazas:

Chica. Otro hay, y si quieres más, / mi madre tiene un pañuelo, / que la trajo aquel señor / que tiene tan guapo el pelo (Ramón de la Cruz, La comedia casera, 1766; CORDE).

18 Véase, al respecto, la respuesta que ofrece la Fundación del Español Urgente a una pregunta formulada sobre el empleo del adjetivo guapo aplicado a cosas (http://www.fundeu.es/consulta/ guapoa-4960/): «Aunque este adjetivo se suele aplicar a las personas, en el habla popular o juvenil se suele emplear para hacer referencia a cosas que son agradables de ver u oír». 
- ¿Qué hace vuestra merced, amigo fray Gerundio? / - ¡Qué he de hacer, señor beneficiado! Habrá una hora que acabé de trasladar un sermón y, cansado ya de escribir, me puse a leer en un libro, el más guapo que he leído ni pienso leer en todos los días de mi vida (José Francisco de Isla, Historia del famoso predicador Fray Gerundio de Campazas alias Zotes, 1758; CORDE).

Según Provencio Garrigós (2016: 189), la expansión polisémica de guapo hacia significados meliorativos tuvo lugar en el paso del siglo xvir al xviI y para mediados de este último comienzan a surgir los significados de 'bello, hermoso' aplicados al rostro de una persona o a cosas, así como el significado de 'acicalado, bien vestido', gracias al influjo que tuvo la vestimenta de la época en algunos sectores de la sociedad. La llegada del siglo xvir supuso el inicio de un cambio en el concepto de belleza, pues esta podía adquirirse con elementos no naturales, como la vestimenta o el peinado, lo que hizo posible que también se les pudiera aplicar a estas realidades la propiedad de ser guapas.

En opinión de Ariza (2007: 40), su aplicación a objetos se empleó tempranamente en la zona asturiana. Para ello, adujo que el ejemplo más antiguo conocido hasta el momento procedía del Padre Isla, quien -como buen asturiano- empleaba guapo también con cosas: «No hallarás un vivar más guapo / que este sitio en que te atrapo». Sin embargo, este uso reiterado por parte de don Simón -quien no era asturiano, sino originario de Aranda de Duero- sugiere una incidencia del fenómeno más amplia para la época. Es probable que quizá este fenómeno llegase a Madrid a través de la inmigración norteña, se acabase generalizando entre la burguesía capitalina y de ahí se irradiase a otros sectores de la sociedad y a otras partes de la Península, como sucedió con otros fenómenos lingüísticos.

Asimismo, se llama la atención en la obra acerca del empleo de algunas formas que sirven para ilustrar las diferencias léxico-semánticas que existían entre ambos grupos de personajes. Véase el ejemplo (9), en el que se señalan como madrileñismos pernil, merluza, cantero ('canto de pan'), esquinazo ('esquina'), portal ('zaguán'), pelleja, (la) vinagra, machacar un cascajo, doler la tripa, (muchos) recados a (donldoña)...

(9)

a. D. Patricio. [...] como ustedes, verbigracia, pernil dicen al jamón y merluza a la pescada, mas para las otras voces no hay tal recurso que valga, si no se va al diccionario

b. D. Patricio. También dicen un cantero de la jerga de las majas (vv. 1098-1104).

a un canto de pan, y llaman el esquinazo a una esquina, portal al zaguán de casa, a la zalea, pelleja y al vinagre, la vinagra.

D. Hilario. ¿Y machaca ese cascajo por parte esas avellanas, 

piñones, nueces o almendras, piensa usté que le va en zaga?
D. Patricio. ¿Y a mi me duele la tripa
D. Hilario. ¿Y lo de muchos recados por me duele el vientre es rana? a don Gil o doña Eufrasia, que me da gana de hacer lo que en ellos nos da gana? (vv. 1111-1126).

Algunas de estas palabras son hoy generales en español, como es el caso de merluza, mientras que otras presentan un uso más restringido, dialectal e, incluso, rural, como el aragonesismo pernil. En el $A D i M$ (mapa 585) se registra aún la forma anticuada pernil junto a jamón en un punto del norte de la comunidad (Mangirón). Como anotan García Mouton y Molina Martos (2017: 44), la informante puntualizó que antes se decía pernil y ahora jamón ${ }^{19}$.

Hay que destacar también ciertas voces y expresiones utilizadas por los personajes madrileños que, en muchos casos, son de acuñación moderna, como el empleo de petar por agradar, me pueden por me enfadan, alivia por aligera, hasta de aqui a luego o hasta otro rato (como antecedentes del actual hasta luego y en lugar del tradicional vaya con dios) e, incluso, la más original saltar en vilo por 'levantar en peso' o 'sacar de quicio' (vv. 465-466).

\section{LA EXPRESIÓN DE LA CORTESÍA Y LAS FORMAS DE TRATAMIENTO}

Aunque las características lingüísticas que se han ido mencionando para el habla de Madrid son numerosas, uno de los elementos más notables se halla en la expresión de la cortesía y el sistema de tratamientos que ponen de manifiesto los personajes. Según se presenta en el texto, a finales del siglo XVIII, parecía existir una clara distinción entre el uso urbano de la Corte y el andaluz, más conservador y tradicional.

Madrid ostentaba lo que se conocía en la época como el «buen tono», las buenas maneras, la etiqueta y la urbanidad. La capital de España se encontraba al frente de las nuevas normas ilustradas de comportamiento y distinción social que llegaban de Europa occidental y estaba también a la vanguardia de las tendencias culturales del país (bailes, peinados, vestimenta...). Erigida como modelo de la modernidad española y no solo como corte regia, capital administrativa y centro económico, Madrid se encargaba de difundir las principales novedades sociales (también lingüísticas) a las zonas más cercanas y, de ahí, al resto de la periferia peninsular.

19 Téngase en cuenta que, por lo general para los encuestados, las «palabras nuevas» son consideradas más prestigiosas y correctas que las «viejas», que se encuentran marcadas negativamente. 
En el Madrid borbónico caló, especialmente, el gusto francés -nótese que Felipe V (1683-1746) era nieto de Luis XIV y había nacido en Versalles-. De Francia se importaban modas como la del cortejo ${ }^{20}$, representada en la obra por el «mozo bonazo» don Pepito -véanse, en concreto, los versos 368-374-, y procedían también los nuevos discursos sociales, como los inspirados en el modelo del l'honnête home, que se reinterpreta entre los personajes madrileños a partir de la idea de que el hombre debía ser, ante todo, una persona honrada ( $c f r$. vv. 431-456). Este ideal alcanza su máxima expresión en don Simón, quien consideraba que todo lo de Madrid (la gente, los bailes, la catedral...) era honrado -frente a lo sevillano, en su opinión, plagado de "picardías e infamas» (v. 426)-.

La capital de España era también una ciudad de inmigrantes en el siglo XVIII - de hecho, la población que había nacido fuera de Madrid había llegado a superar el $40 \%$ durante toda la centuria (Carrasco Martínez 2010: 158)-. A la ciudad llegaron personas de diversos orígenes atraídas por las posibilidades de trabajo (especialmente en la Administración o en alguna casa nobiliaria como personal de confianza) y de ascenso económico y social. Tales nuevos ciudadanos, deseosos de ver sus aspiraciones vitales alcanzadas, intentaron encontrar un espacio social distintivo mediante la aproximación e imitación de las clases más pudientes. Sus intentos por emular los usos, modos y costumbres de las clases altas los llevaron a reproducir no solo la forma y el lujo del vestir -adviértase que las telas traídas del extranjero tuvieron que ser prohibidas para incentivar el producto nacional-, sino los gestos, signos, comportamientos y, por supuesto, los usos lingüísticos de la corte madrileña.

En cuanto al sistema de trato, dichos hijos prohijados de Madrid se acercaron al uso de «los grandes» (v. 1177) adoptando su modo de dirigirse a los demás: de una parte, trataban con cierto desprecio a los inferiores, de los que querían y debían diferenciarse; de otra, usaban un trato de mayor confianza con las clases poderosas, o mejor situadas socialmente, para intentar alcanzar un estatus igualitario. Así se puede ver en los fragmentos siguientes (10):

$\begin{array}{ll}\text { a. D. Patricio. } & \begin{array}{l}\text { Todos estos caballeros } \\ \text { que bajan de la otra banda } \\ \text { nos la echan de proteción } \\ \text { y de autoridad. Se tratan } \\ \text { tú por tú con los ministros } \\ \text { y al rey tienen de las barbas (vv. 751-756). } \\ \text { Me agrada el trato de corte, } \\ \text { es llano como la palma } \\ \text { de la mano (vv. 321-323). }\end{array} \\ \text { b. D. Patricio. } & \text { P. Pues es llaneza. }\end{array}$

${ }^{20}$ Por cortejo se conocía al individuo que acompañaba a las mujeres casadas de cierta posición social en el siglo xviII. Sobre esta moda y las repercusiones sociales que tuvo, véase el trabajo de Martín Gaite (1972). 

D. ${ }^{a}$ María.
Es un trato
entre desprecio y confianza.
D. ${ }^{a}$ Petra. Pues así lo hacen los grandes.
D. ${ }^{a}$ María. ¿YY porque los grandes lo hagan
D. Patricio. Deje usté los grandes, Paca, que son tan altos que a ellos tan solo el respeto alcanza. [...]
D. Hilario. El grande no halla, ni tiene otro tratamiento, que dar a gente mediana o menos, y esta o la otra, cual mona, imitarlos rabia (vv. 1175-1182; 1186-1190).
d. D. . Paquita. Lo mismo trato yo a un grande que a usté.
D. ${ }^{a}$ Petra.
D. ${ }^{a}$ Paquita. esta como a mí. [...] No se gastan allá embustes ni etiquetas, ni se anda con soy o no.
D. ${ }^{a}$ María. Según eso, allá se igualan las trazas, y con los gentiles hombres alternan los rapabarbas, o se sientan los lacayos en tertulia con sus amas. [...]
D. Hilario. Sí, señor. Allá se dobla punta con punta la vara y verduleras y grandes se tutean en las plazas.
D. Patricio. ¡Hombre de Dios!, aun si fuera grandes y cómicas... Vaya, que allí se unen los extremos (vv. 327-329; 331-338; 345-351).

Aunque puedan parecer desmesuradas estas afirmaciones, lo que parece seguro es que el Madrid de finales del XVIII fue un entorno proclive al contacto entre clases y a la relajación del encorsetado sistema de trato empleado dos siglos atrás. De hecho, como afirma Vázquez Marín (1992: 226-227), en las últimas décadas del setecientos, los jóvenes esnobs de gustos foráneos se dedicaron a imitar a los majos y majas madrileñas. Para determinadas fiestas, se vestían con el traje típico, reivindicando su casticismo. El majismo hacía estragos en Madrid y en las grandes ciudades de provincia. Se invirtió entonces el proceso, puesto que los usos extranjerizantes, que no desaparecieron a finales de siglo, quedaron diluidos en algún que otro sector de la aristocracia. Lejos quedaban ya las formas de la antigua etiqueta borgoñona impuesta por Carlos I o las pragmáticas sobre los tratamientos de Felipe II. En el nuevo discurso desapareció la tradicional obsesión por la jerarquía social característica de la vieja urbanidad. Como afirma Cruz (2010: 332), el llamado "principio de jerarquía se sustituyó por la noción de "distinción”". 
Esta situación trajo consigo que en Madrid se abandonaran determinadas construcciones deferenciales de corte tradicional y se avanzara hacia formas de trato más solidarias que en otras zonas de España. Dichos cambios sociales afectaron a las formas de saludo y despedida de la época (11):

a. D. Hilario. Que las tenga usté muy buenas.

D. Juanito. ¡Ceremonias excusadas!

D. Hilario. ¿Ceremonia es saludarse?

D. JuAnito. Bien haya Madrid, se anda, se entra y sale, se va y viene

D. Hilario. ¡Qué viva la cortesía $\mathrm{y}$ a nadie se habla palabra.

b. D. ${ }^{a}$ Paquita. ¿Qué hora es ya?

D. Pepito. Dadas las diez.

D. ${ }^{a}$ PaQuita. Alivia, chica.

D. Hilario. ¿Está mala?

D. ${ }^{a}$ Paquita. No, señor, que vamos pronto.

D. Hilario. ¿Alivia es camina, marcha?

Hasta ahora no lo sabía (vv. 1434-1438).

Y, como es lógico, también tuvieron su reflejo en el esquema de tratamiento:

(12)

D. Patricio. Llaman don Juan y don Pedro, cual mayordomo de casa, a los hombres de respeto, decir la Pepa y la Juana a las mujeres de forma como si fueran gitanas y don Juanito y Pepito a gentes llenas de barbas es abuso intolerable y de muy pésima crianza, que la moda y la costumbre

D. ${ }^{a}$ María. Acá se llama Juanico no salva.

a un nińo, don Juan se llama a un portero, Juan a un criado, Juanillo a un pillo sin capa, señor Juan a un mandadero, tío Juan a gente de manta y señor don Juan a un hombre decente con quien se trata, se da usía al que la tenga y excelencia al que la traiga y los demás tratamientos que exigen las circunstancias. 

D. ${ }^{a}$ Paquita.
Esas sí son ceremonias.
D. ${ }^{a}$ María.
Es buen modo y buena cria[n]za (vv. 1149-1174).

En este fragmento (12) se expone, de manera muy clara, el funcionamiento completo del sistema de trato nominal y se reconstruyen los valores asociados a cada una de las formas. Para los sevillanos, las diferencias entre los tratamientos dependían aún de la condición social de un individuo (nobleza, ocupación, edad), mientras que en Madrid el tratamiento apelativo funcionaba de manera distinta: se hacía un uso extensivo de don (o doña) junto al antropónimo (don Juan, don Pedro...) para referirse con respeto a cualquier individuo adulto; para la confianza, de manera coloquial y aunque fuesen personas adultas, se les podía añadir el sufijo -ito al nombre propio (don Juanito, don Pepito...), sin que, por ello, considerasen que se les estaba faltando al respeto ${ }^{21}$; para dirigirse a las mujeres, en general, se podía emplear el artículo junto al antropónimo (la Pepa, la Juana...), incluso al hablar de las mujeres nobles (13).

(13)
D. ${ }^{a}$ Paquita.
¿No te acuerdas
de los dos de la de Alba?, ¿de los de la Peñafiel, de la de Híjar, la Miranda de la Arión, la de Abrantes?...
D. Hilario. ¡Tómate esa confianza!, ¡la Peñafiel, la Arión! Con qué llaneza las tratan, [...] (vv. 311-318).

Es interesante destacar el desprestigio que la fórmula don/doña+nombre propio (14) poseía para los andaluces del XviII, pues estos solo la empleaban para dirigirse a los criados o empleados de la casa (mayordomo, cocinera, ama de leche, etc.). Únicamente si se le adjuntaba el sustantivo señor/a, dicha construcción alcanzaba un valor respetuoso.
D. ${ }^{a}$ Petra.
Nada, doña María.
D. ${ }^{a}$ MaríA.
Tal doña... (aparte)
María, ¿como si hablara
quizá con la cocinera
o ama de leche de casa? (vv. 550-554).

${ }^{21}$ Sánchez-Prieto Borja y Vázquez Balonga (2019: 129) señalan también el uso de este diminutivo, con valor afectivo, en antropónimos referidos a una persona adulta en los documentos de beneficencia madrileños, aunque también se localiza en muchos nombres comunes, lo que "parece corroborar el cambio de -illo a -ito, al menos en el habla madrileńa». En el xix el uso de los diminutivos en personas adultas de clase alta es notorio en algunos autores como Galdós (Náñez Fernández 1973: 293). Acerca de su utilización en el habla actual de Madrid, véase Paredes García (2015). 
Como miembros de dos comunidades de habla diferenciadas, ambos grupos de personajes eran conscientes de las disparidades que había entre ellos. Así, la directa manera de hablar de Madrid no era bien acogida por quienes mantenían un patrón tradicional más cortés ${ }^{22}$ y se encontraban más alejados del foco de irradiación de la capital, como era el caso de los personajes sevillanos (15).
a. D. Hilario. Según eso, ‘allá se dicen
D. Simón. Sí, señor, la ingenuidad,
b. D. ${ }^{a}$ Paquita
Pues sea bien o mal hecho, en Madrid se hace así y basta. el pan, pan y el agua, agua (vv. 981-984).
D. ${ }^{a}$ María.
La razón no me hace fuerza, y como soy sevillana, las modales de mi tierra me parecen más urbanas (vv. 1199-1204).

Este rechazo trajo consigo que cada grupo prefiriera el uso hablado en «su lugar», lo que pudo haber originado patrones de trato diferenciados para Madrid y Sevilla, como ocurrió con los tratamientos plurales vosotros y ustedes (cfr. Fernández Martín 2013) y las formas empleadas para dirigirse a los progenitores en el siglo XIX (cfr. García Godoy 2010). Sin duda, las normas de comportamiento social (y, como ejemplo de ello, el sistema de tratamientos) estaban viviendo en el XviII un auténtico proceso de reajuste de las viejas estructuras tradicionales. Los cambios que se iniciaron en este período determinaron drásticamente su devenir en español y sus distintos resultados dialectales.

\section{CONCLUSIONES}

El presente análisis ha demostrado la relevancia de esta obra como testimonio histórico-social y lingüístico del habla de Madrid y, en especial, en lo que atañe al estudio de su caracterización dialectal. Los fenómenos lingüísticos señalados por González de León a finales del siglo XviII parecen coincidir con la evolución de esta variedad, dado que algunos de ellos siguen activos en la actualidad como rasgos dialectales, tales como las distintas soluciones en la pronunciación de la - $d$ final, y otros se han generalizado en español -al menos en el de España-, como el uso de a por o el adjetivo guapo aplicado a cosas, gracias, sin duda, a lo que representa Madrid para la evolución de la historia de la lengua española moderna.

${ }^{22}$ Hoy día es conocida la caracterización del habla madrileña como descortés, brusca o grosera por los hispanohablantes de otras regiones del mundo hispánico ( $c f r$. Molina Martos 2010b; Pesqueira 2012; Sancho Pascual 2013). Sin embargo, este asunto ha sido menos atendido a lo largo de la historia de la lengua. 
Asimismo, los datos aportados por esta obra han servido para adelantar al XVIII la cronología propuesta para la locución a por seguida de verbos que indican movimiento, hasta el momento situada en el ochocientos, así como para ofrecer lo que parece ser el primer testimonio de la pronunciación diptongada de por ahi.

Por otra parte, las diferencias señaladas por González de León para ambos grupos humanos revelan las disparidades que existieron entre el uso lingüístico dieciochesco de Madrid y Sevilla, especialmente, en lo que se refiere a los distintos esquemas de cortesía manejados. A la vanguardia en solidaridad comunicativa se situaba Madrid, que funcionó en el siglo XviII como modelo lingüístico de prestigio. Frente a ella se encontraban los usos de provincias, como los sevillanos, que eran mucho más corteses y seguían reflejando el modelo de urbanidad tradicional sustentado por la jerarquía social.

En suma, consideramos que ha quedado de manifiesto la importancia que presenta la obra Los madrileños adoptivos para el estudio de la historia de la lengua espańola a finales del xviII y, en concreto, de la variedad madrileńa, habla esta que ha ejercido una notable influencia en la configuración de la norma lingüística del español moderno y sin cuyo estudio no puede entenderse plenamente la historia más reciente de nuestro idioma. 


\section{BIBLIOGRAFÍA}

ADiM = Pilar García Mouton e Isabel Molina Martos (2015): Atlas Dialectal de Madrid, Madrid: CSIC. URL: http://adim.cchs.csic.es/es; 15/02/2019.

ALeCMAn = Pilar García Mouton y Francisco Moreno Fernández (dirs.) (2003): Atlas Lingüistico (y etnográfico) de Castilla-La Mancha, Alcalá de Henares: Universidad de Alcalá. URL: http://www2.uah.es/alecman; 19/02/2019.

Aguilar Piñal, Francisco (1974): Sevilla y el teatro en el siglo XVIII, Oviedo: Centro de Estudios del Siglo XVIII.

Aguilar Piñal, Francisco (1986): Bibliografía de autores españoles del siglo XVIII (vol. iv), Madrid: CSIC.

Ariza Viguera, Manuel (2007): «La belleza», en Luis Luque Toro (ed.), Léxico español actual. Actas del I Congreso Internacional de Léxico Español Actual (Venecia-Treviso, 14-15 de marzo de 2005), Venecia: Università Ca'Foscari di Venezia, 37-48.

Cano Aguilar, Rafael (2004): "Cambios en la fonología del español durante los siglos Xvi y Xviı», en Rafael Cano Aguilar (coord.), Historia de la lengua española, Barcelona: Ariel, 825-857.

Carbajo Isla, María F. (1985): «La inmigración a Madrid (1600-1850)», Reis. Revista Española de Investigaciones Sociológicas 32: 67-100.

Carrasco Martínez, Adolfo (2010): «Ciudad y sociedad en el Madrid del siglo xviII», Cuadernos de investigación histórica 27: 157-182.

Carricaburo, Norma (2010): «La variación acentual en el español de Buenos Aires», Boletín de la Academia Argentina de Letras LXXV (309-310): 363-372.

Company Company, Concepción (2007): El siglo XVIII y la identidad lingüistica de México, México: Academia Mexicana de la Lengua y Universidad Nacional Autónoma de México.

Company Company, Concepción y Rodrigo Flores Dávila (2017): «Género textual, diacronía y valoración de un cambio sintáctico. A por con verbos de movimiento", BRAE 97 (315): 203-239.

$C O R D E=$ Real Academia Española: CORDE. Corpus diacrónico del español. URL: http://corpus. rae.es/cordenet.html; 20/04/2020.

CORDIAM= Academia Mexicana de la Lengua: Corpus Diacrónico y Diatópico del español de América. URL: http://www.cordiam.org; 20/04/2020.

Cruz, Jesús (2010): «La definición de los modelos de conducta burguesa en la España del siglo XIX», en Pierre Civil y Françoise Crémoux (coords.), Nuevos caminos del hispanismo: actas del XVI Congreso de la Asociación Internacional de Hispanistas (París, del 9 al 13 de julio de 2007) (vol. 2 [CD ROM]), Madrid: Iberoamericana, 332.

Di Tullio, Ángela (2013): "Ahi y por ahí en el español de la Argentina», Anuario de Letras. Lingüistica y Filología I (2): 329-356.

$D P D=$ Real Academia Española y Asociación de Academias de la Lengua Española (2005): Diccionario panhispánico de dudas [versión electrónica], Madrid: Santillana. URL: https:// www.rae.es/dpd; 30/03/2019.

Fernández Martín, Elisabeth (2013): La oposición vosotros/ustedes en la historia del español peninsular (1700-1931), Granada: Universidad de Granada. URL: http://hdl.handle. net/10481/24018; 21/04/2018.

Fernández Martín, Elisabeth (2016a): Sevilla frente a Madrid en el siglo XVIII: «Los madrileños adoptivos» (1790) de Antonio González de León, Madrid: CSIC. 
Fernández Martín, Elisabeth (2016b): «El interés de Los madrileños adoptivos de Antonio González de León para la Historia de la lengua española», en Cristóbal López Álvarez y M. a del Rosario Martínez Navarro (eds.), Diálogos entre la lengua y la literatura, Sevilla: Vitela, 51-70.

FICHERO GENERAL = REAL ACADEMIA EsPAÑola (2013-): Fichero general de la lengua española [recurso en línea], Madrid: RAE. URL: https://webfrl.rae.es/fichero.html; 20/05/2020.

FLórez, Luis (1966): «Apuntes sobre el español de Madrid en el año de 1965», Thesaurus XXI (1): 156-171.

García Godoy, María Teresa (2010): «El tratamiento a los progenitores en el español peninsular (siglo XIX). Contraste de dos variedades geográficas», en Martin Hummel, Bettina Kluge y María Eugenia Vázquez Laslop (eds.), Fórmulas y formas de tratamiento en el mundo hispánico, México D.F.: El Colegio de México, Karl Franzens y Universität Graz, 595-617.

García González, Javier (2018): «Aportación al estudio del habla de Madrid en los siglos XviII y XIX», en María Luisa Arnal Purroy et al. (coord.), Actas del X Congreso Internacional de Historia de la Lengua Española (Zaragoza, 7-11 de septiembre de 2015) (vol. 2), Zaragoza: Institución Fernando el Católico, 1571-1588.

García Mouton, Pilar (2007 [1994]): Lenguas y dialectos de España, 5.a ed., Madrid: Arco Libros.

García Mouton, Pilar e Isabel Molina Martos (2017): Las hablas rurales de Madrid. Etnotextos, Berna: Peter Lang.

GonzÁlez Ollé, Fernando (2003): «Apuntes para la historia lingüística de Madrid», en Carmen Alemany Bay et al. (coord.), con Alonso Zamora Vicente: Actas del Congreso Internacional "La Lengua, la Academia, lo Popular, los Clásicos, los Contemporáneos» (vol. II), Alicante: Universidad de Alicante, 709-724.

Hernández Alonso, César (1996): «Castilla La Vieja», en Manuel Alvar (dir.), Manual de dialectología hispánica. El español de España, Barcelona: Ariel, 197-212.

Herrera Navarro, Jerónimo (2008): «Saineteros ilustrados», en Javier Huerta Calvo (coord.), Historia del teatro breve en España, Madrid-Frankfurt: Iberoamericana Vervuert, 801-813.

Martín Gaite, Carmen (1972): Usos amorosos del dieciocho en España, Madrid: Siglo XXI.

Matute y Gaviria, Justino (2007 [1888]): Hijos de Sevilla señalados en santidad, letras, armas, artes o dignidad [edición facsimilar], Sevilla: Extramuros.

Menéndez Pidal, Ramón (1962): «Sevilla frente a Madrid. Algunas precisiones sobre el español de América», 99-165, en Diego Catalán (ed.), Miscelánea Homenaje a André Martinet. Estructuralismo e historia (vol. III), La Laguna: Universidad de La Laguna, 99-165.

Molina Martos, Isabel (2006): «Innovación y difusión del cambio lingüístico en Madrid», Revista de Filología Española, LXXXVI (1): 127-149.

Molina Martos, Isabel (2010a): «El español en el centro peninsular», en Esteban T. Montoro del Arco y Juan Antonio Moya Corral (eds.), El español en contexto. Actas de las XV Jornadas sobre la Lengua Española y su enseñanza, Granada: Editorial Universidad de Granada, 87-103.

Molina Martos, Isabel (2010b): «Procesos de acomodación lingüística de la inmigración latinoamericana en Madrid», Lengua y migración 2 (2): 27-48.

Molina Martos, Isabel (2015): «La variable sociolingüística /-s/ en el distrito de Vallecas (Madrid)», en Ana María Cestero Mancera, Isabel Molina Martos y Florentino Paredes García (coords.), Patrones sociolingüisticos de Madrid, Berna: Peter Lang, 91-116. 
Moreno Fernández, Francisco (1996): «Castilla La Nueva», en Manuel Alvar (dir.), Manual de dialectología hispánica. El español de España, Barcelona: Ariel, 213-232.

Moreno Fernández, Francisco (2004): «Cambios vivos en el plano fónico del español: variación dialectal y sociolingüística», en Rafael Cano Aguilar (coord.), Historia de la lengua española, Barcelona: Ariel, 973-1009.

NáŃEz Fernández, Emilio (1973): El diminutivo: historia y funciones en el español clásico y moderno, Madrid: Gredos.

Navarro Tomás, Tomás (2004 [1918]): Manual de pronunciación española, 23. a ed. Madrid: CSIC.

$N G L E=$ Real Academia Española y Asociación de Academias de la Lengua Española (2009): Nueva gramática de la lengua española. Morfología y Sintaxis, Madrid: Espasa. URL: http:// aplica.rae.es/grweb/cgi-bin/buscar.cgi; 18/02/2019.

NTLLE = Real Academia Española de la Lengua: Nuevo Tesoro Lexicográfico de la Lengua Española [recurso en línea]. URL: http://ntlle.rae.es/ntlle/SrvltGUILoginNtlle; 10/02/2019.

Paredes García, Florentino (2006): «Dialectología y sociolingüística en Madrid», en Ana María Cestero Mancera, Isabel Molina Martos, Florentino Paredes García (coords.), Estudios sociolingüisticos del español de España y América, Madrid: Arcolibros, 221-232.

Paredes García, Florentino (2015): «Funciones subjetivadoras del diminutivo en el habla de Madrid», en Ana María Cestero Mancera, Isabel Molina Martos y Florentino Paredes García (coords.), Patrones sociolingüisticos de Madrid, Berna: Peter Lang, 117-153.

Paredes García, Florentino e Isabel Molina Martos (2019): «La configuración de la norma madrileña desde la dialectología y la sociolingüística», en Eugenio Bustos Gisbert y Juan Pedro Sánchez Méndez (coords.), Configuración histórica de las normas del castellano, Valencia: Tirant lo Blanch.

Penny, Ralph (2004): «Evolución lingüística en la Baja Edad Media: evoluciones en el plano fonético», en Rafael Cano Aguilar (coord.), Historia de la lengua española, Barcelona: Ariel, 593-612.

Pensado Ruiz, Carmen (2000): «Sobre la historia del ensordecimiento final», Estudis romànics 22: $29-57$.

Pesqueira Barragán, Dinorah (2012): Acomodación y cambio lingüistico en las situaciones de contacto dialectal [tesis doctoral], México D.F.: El Colegio de México. URL: https://colmex. userservices.exlibrisgroup.com/view/delivery/52COLMEX_INST/1265004430002716? anguage $=$ es; $23 / 02 / 2020$.

Provencio Garrigós, Herminia (2016): «Cambio semántico meliorativo de guapo: de la percepción olfativa y gustativa a la percepción visual», Anuari de Filología. Estudis de lingüistica 6: 161-194.

Quilis, Antonio (1966): «Notas para el estudio del habla de Madrid y su provincia», Anales del Instituto de Estudios Madrileños 1: 365-372.

Sánchez-Prieto Borja, Pedro y Delfina Vázquez Balonga (2019): La beneficencia madrileña: lengua y discurso en los documentos de los siglos XVI al XIX, Madrid: Ediciones Complutense.

SAncho Pascual, María (2013): Integración sociolingüistica de los inmigrantes ecuatorianos en Madrid [tesis doctoral], Alcalá de Henares (Madrid): Universidad de Alcalá de Henares. URL: https://ebuah.uah.es/dspace/bitstream/handle/10017/20139/TESIS_SANCHO_PASCUAL.pdf?sequence=1\&isAllowed=y; 21/02/2020.

VÁzQuez Marín, Juana (1992): El Madrid cotidiano del siglo XVIII [tesis doctoral], Madrid: Universidad Complutense de Madrid. 
